\title{
Openness to and preference for attributes of biologic therapy prior to initiation among patients with rheumatoid arthritis: patient and rheumatologist perspectives and implications for decision making
}

This article was published in the following Dove Press journal:

Patient Preference and Adherence

16 June 2016

Number of times this article has been viewed

\section{Susan C Bolge' \\ Amir Goren ${ }^{2}$ \\ Duncan Brown ${ }^{2}$ \\ Seth Ginsberg ${ }^{3}$ \\ Isabel Allen ${ }^{4}$}

'Health Economics \& Outcomes Research, Janssen Scientific Affairs, LLC, Raritan, NJ, ${ }^{2}$ Health Outcomes Practice, Kantar Health, New York, ${ }^{3}$ Global Healthy Living Foundation, Upper Nyack, NY, ${ }^{4}$ Department of Biostatistics \& Epidemiology, University of California San Francisco, San Francisco, CA, USA
Correspondence: Amir Goren Health Outcomes Practice, Kantar Health, II Madison Ave, Floor I2, New York, NY I00I0, USA

Tel + I 2127063909

Fax + I 2126477659

Email amir.goren@kantarhealth.com
Purpose: Despite American College of Rheumatology recommendations, appropriate and timely initiation of biologic therapies does not always occur. This study examined openness to and preference for attributes of biologic therapies among patients with rheumatoid arthritis (RA), differences in patients' and rheumatologists' perceptions, and discussions around biologic therapy initiation.

Patients and methods: A self-administered online survey was completed by 243 adult patients with RA in the US who were taking disease-modifying antirheumatic drugs (DMARDs) and had never taken, but had discussed biologic therapy with a rheumatologist. Patients were recruited from a consumer panel $(n=142)$ and patient advocacy organization $(n=101)$. A separate survey was completed by 103 rheumatologists who treated at least 25 patients with RA per month with biologic therapy. Descriptive and bivariate analyses were conducted separately for patients and rheumatologists. Attributes of biologic therapy included route of administration (intravenous infusion or subcutaneous injection), frequency of injections/infusions, and duration of infusion.

Results: Over half of patients (53.1\%) were open to both intravenous infusion and subcutaneous injection, whereas rheumatologists reported $40.7 \%$ of patients would be open to both. Only $26.3 \%$ of patients strongly preferred subcutaneous injection, whereas rheumatologists reported $35.2 \%$. Discrepancies were even more pronounced among specific patient types (eg, older vs younger patients and Medicare recipients). Among patients, 23\% reported initiating discussion about biologics and 54\% reported their rheumatologist initiated the discussion. A majority of rheumatologists reported discussing in detail several key aspects of biologics, whereas a minority of patients reported the same.

Conclusion: Preferences differed among patients with RA from rheumatologists' perceptions of these preferences for biologic therapy, including greater openness to intravenous infusion among patients than assumed by rheumatologists and relative lack of discussion about key aspects of biologic therapy perceived by patients. There is a need for more open communication about treatment options, which may encourage more appropriate, timely transition to biologic therapy.

Keywords: intravenous infusion, subcutaneous injection, biologics, discussions about treatment, patient-provider communication

\section{Introduction}

Rheumatoid arthritis (RA), a chronic progressive autoimmune condition, is estimated to affect between $0.5 \%$ and $1.0 \%$ of the adult population globally. ${ }^{1}$ The prevalence 
of arthritis overall has been rising, with RA accounting for $17.9 \%$ of those diagnosed with arthritis, according to 1999-2008 data from the US National Health and Nutrition Examination survey. ${ }^{2}$ RA is most prevalent among older individuals and females. ${ }^{1}$ RA has been found to have an extensive impact on mortality and morbidity. ${ }^{3}$ For instance, RA leads to pain, morbidity, joint damage, a decline in functional abilities, a high rate of comorbidities, and higher rates of mortality. ${ }^{1,4,5}$ In addition to the direct costs of health care associated with managing these negative outcomes, significant indirect costs are incurred by RA, such as a loss in work productivity. ${ }^{6,7}$

Traditional disease-modifying antirheumatic drugs (DMARDs), most commonly methotrexate, have demonstrated efficacy in the management of RA and are used by a majority of patients. However, the American College of Rheumatology recommends initiation of biologic therapy in patients who are not adequately responding to DMARDs (ie, moderate to high disease activity with methotrexate monotherapy lasting 3 months or DMARD combination therapy). ${ }^{3,8}$ Biologic therapies have been shown to be highly effective in treating RA, including managing symptoms ${ }^{9,10}$ and halting progression of structural damage and physical disability due to RA. ${ }^{11,12}$ This reduction in symptom burden and structural damage, in turn, leads to decreases in the level of disability ${ }^{9}$ and cost of care ${ }^{10}$ faced by patients with RA. Biologic therapies have also been associated with more quality-adjusted life years, in comparison with traditional DMARDs. ${ }^{10}$ Moreover, biologic therapies have been associated with reduced disease activity and improved functional abilities of RA sufferers, as well as increased quality of life when used alone and in combination with methotrexate or other DMARDs. ${ }^{13-15}$ It is anticipated that demand for biologic therapies will increase from both patients and prescribers as more evidence is presented about the associated outcomes. ${ }^{10}$

Nonetheless, research indicates that appropriate and timely escalation of treatment from DMARDs to biologic therapies does not always occur, in spite of their demonstrated effectiveness. ${ }^{16}$ Also, rheumatologists and patients have been found to differ with respect to instrumental factors in care escalation decisions. ${ }^{16}$ Biologic agents are currently administered via two routes: subcutaneous injection (SQ) and intravenous infusion (IV). SQ and IV administration of biologic agents differs not only in routes of administration but also in dosing schedules ${ }^{17}$ and costs, ${ }^{18}$ which are associated with patients' preferences and corresponding persistence in treatment utilization. Additionally, injection issues (depending on route of administration and agent type) have been shown to influence patients' utilization of biologic therapies. ${ }^{19}$ Prior research suggests variations in dosing frequency, delivery type, $\mathrm{pH}$ levels, and needle size may all influence whether patients discontinue using a particular biologic agent. ${ }^{19}$ Factors such as safety, efficacy, and patients' preferences for various aspects of the biologic therapies have also been identified as integral to patients' decision making regarding RA treatment. ${ }^{20}$

Frequency of dosing and route of administration have also been demonstrated to play a significant role not only in persistence with therapies but also in the initial decisionmaking process regarding biologic therapy. ${ }^{3}$ For example, one study found that route of administration was the most important feature for patients in choosing a biologic therapy. ${ }^{21}$ This study also found that SQ was the most preferred route of administration by both those currently receiving and those not yet receiving biologic therapies. In addition to preferring SQ route of administration, patients preferred the longest possible interval between administrations of treatment. Another two studies identified frequency of dosing as the second or third most preferred attribute of biologic therapy reported by patients with RA. . $^{22,23}$

Physician guidance is another factor influencing patients' decisions regarding RA treatment. ${ }^{24}$ In fact, a rheumatologist's experience with a particular therapy has been identified as one of the most important factors taken into consideration by both patients and rheumatologists when deciding on a biologic therapy. ${ }^{22}$ Many studies have examined how patients and rheumatologists approach the decision to escalate treatment to biologic therapies. ${ }^{25-27}$ However, a majority of these studies represented either rheumatologists' or patients' perspectives alone, and many of these studies examined only a limited number of factors influencing the decision-making process. Other studies have noted the importance of information for patients with RA regarding their treatment-related decision making, with a high level of need for information identified. ${ }^{28,29}$ Thus, there is a need for open communication and for rheumatologists to have a clear understanding of patients' preferences.

The primary aim of the current study was to examine openness to and preference for attributes of biologic therapies among patients with RA prior to biologic therapy initiation. A secondary aim was to examine rheumatologist perceptions of patient openness to and preference among biologic therapies. A related aim was to identify gaps between rheumatologist and patient perceptions about biologic therapies and corresponding discussions about biologic therapies, as well as implications for patient-rheumatologist dialogue and 
the decision-making process surrounding biologic therapy treatment for RA.

\section{Materials and methods Sample}

The sample for this study consisted of 243 patients with RA in the US recruited from a consumer panel, Lightspeed Research $(n=142)$, and a patient advocacy organization, Creaky Joints $(n=101)$. Patient inclusion criteria were as follows: self-reported diagnosis of RA by a rheumatologist, visited a rheumatologist for RA in the past 6 months, currently taking DMARDs, never taken a biologic therapy, aware of and discussed biologic therapy with rheumatologist, aged 18 years or older, residing in the US, able to read/write English, and provided online informed consent. Rheumatologist inclusion criteria were as follows: specialty in rheumatology, board certified or eligible, 2-25 years postresidency practice as a rheumatologist, at least $50 \%$ time spent providing direct patient care, at least 50 patients with RA treated per month, at least 25 treated with biologic therapy, not employed by or providing consulting services to any pharmaceutical company, and not working for government. The study protocol was reviewed and approved by the Essex Institutional Review Board (Lebanon, NJ, USA).

\section{Measures}

Patient data were collected via a self-administered online survey $\sim 30$ minutes in length. Rheumatologist data were also collected via a self-administered online survey $\sim 15$ minutes in length (see Table S1 for an outline of survey items).

Openness to route of administration (IV and SQ) was assessed for patients via a 5 -point Likert scale $(1=$ not at all open; $2=$ not very open; $3=$ somewhat open; $4=$ very open; and 5= extremely open), with 3-5 categorized as "open". Patient openness to route of administration as reported by rheumatologists was assessed by requiring rheumatologists to report the proportion of their patients estimated to be open to IV only, SQ only, both, or neither. Patient openness to specific biologic therapy attributes (ie, duration of infusions and frequency of injections/infusions based upon the characteristics of approved biologic treatments in the US at the time of the study) was also assessed for both patients and rheumatologists via the 5-point Likert scale described above. Mean scores were calculated to determine patient and rheumatologist perceptions of biologic treatment characteristics.

Patient preference was assessed from both the patients' and rheumatologists' perspective via allocation of 100 points across various biologic therapy options. Mean scores were calculated to determine patient and rheumatologist perceptions of preferences. Preference for route of administration (IV and SQ) was assessed for patients via a 5-point Likert scale ranging from $1=$ strongly prefer self-injection to $5=$ strongly prefer IV infusion, with 1-2 or 4-5 categorized as preferring one route or the other. Patient preference for route of administration was assessed for rheumatologists via proportion of their patients estimated to fall within each of the five aforementioned preference categories.

Level of discussion around treatment was rated by both patients and rheumatologists as "not discussed at all", "discussed somewhat", or "discussed in detail".

\section{Statistical analyses}

Descriptive analyses (means and standard deviations for continuous variables and percentages and frequencies for categorical variables) were conducted for patient demographics and openness to and preference among biologic therapies and routes of administration, as well as other patient and rheumatologist attitudes related to treatment perceptions and decision-making preferences. The statistical significance (two-tailed $P<0.05$ ) of differences across groups on measures assessed in a compatible manner (ie, consumer panel vs advocacy group comparisons) was assessed via pairwise $t$-tests for mean (continuous variables) and chi-square or binomial proportion tests for frequencies (categorical variables).

Patients recruited via Creaky Joints and the consumer panel were initially compared in terms of various characteristics in order to understand sample differences and inform the breadth of representativeness captured in the current study. However, as the objective of the study was to analyze patients on the whole vis-à-vis rheumatologists, patients were subsequently included as a single category for the majority of the analysis.

\section{Results}

The mean age of patients in the total sample was 52.5 years (Table 1). Mean years since onset of RA symptoms reported by patients was 12.90 years. Patients in this sample had been discussing biologic therapies with their rheumatologists on average for 1.32 years over an average of 2.67 visits. Patients recruited through the consumer panel were on average older (mean $=57.3$ years) than those recruited through Creaky Joints, the patient advocacy group (mean $=45.8$ years), $P<0.05$. The majority of the total patient sample was female $(85.2 \%)$. However, Creaky Joints patients were more frequently female $(93.1 \%)$ in comparison with the consumer panel (79.6\%), $P<0.05$. The majority of both Creaky Joints and consumer panel patients were white $(88.1 \%$ and $83.8 \%$, respectively). About a third of patients $(32.9 \%)$ were insured 
Table I Patient demographics and disease characteristics

\begin{tabular}{|c|c|c|c|c|c|c|}
\hline & \multicolumn{2}{|c|}{ Creaky Joints panel } & \multicolumn{2}{|c|}{ Consumer panel } & \multicolumn{2}{|l|}{ Total } \\
\hline & $\% /$ Mean \pm SD & $\mathbf{N}$ & $\% /$ Mean \pm SD & $\mathbf{N}$ & $\% /$ Mean \pm SD & $\mathbf{N}$ \\
\hline Age & $45.77 * \pm 12.22$ & 101 & $57.27 \pm 11.63$ & 142 & $52.49 \pm 13.14$ & 243 \\
\hline Female & 93.1 & $94 *$ & 79.6 & 113 & 85.2 & 207 \\
\hline White & 88.1 & 89 & 83.8 & 119 & 85.6 & 208 \\
\hline Married & 58.4 & 59 & 56.3 & 80 & 57.2 & 139 \\
\hline Employed full-time & 33.7 & $34 *$ & 19.7 & 28 & 25.5 & 62 \\
\hline College degree & 59.4 & $60 *$ & 43.0 & 61 & 49.8 & 121 \\
\hline Medicare insurance & 20.8 & $21^{*}$ & 41.5 & 59 & 32.9 & 80 \\
\hline Years since start of RA symptoms & $10.18 * \pm 9.99$ & 101 & $14.83 \pm 12.50$ & 142 & $12.90 \pm 11.73$ & 243 \\
\hline Joint damage due to RA & 60.4 & 61 & 65.5 & 93 & 63.4 & 154 \\
\hline
\end{tabular}

Note: $* P<0.05$ for comparisons across panels, within each row.

Abbreviations: RA, rheumatoid arthritis; SD, standard deviation.

with Medicare, a lower proportion in the Creaky Joints (20.8\%) than in the consumer (41.5\%) panel, $P<0.05$. Nearly half of patients (49.8\%) had at least a college degree $(59.4 \%$ of Creaky Joints vs $43.0 \%$ of consumer panel, $P<0.05$ ). About a third (34.2\%) of patients were employed full-or part-time, a greater proportion in the Creaky Joints (47.5\%) than in the consumer (24.6\%) panel, $P<0.05$. At the same time, a lower proportion of patients were retired in the Creaky Joints (6.9\%) than in the consumer (33.1\%) panel, with $22.2 \%$ retired in total, $P<0.05$.

The mean age of rheumatologists was 49.2 years (Table 2). Female rheumatologists composed $27.2 \%$ of the sample. The majority were white $(72.8 \%)$. Mean years in practice as a rheumatologist was 14.4 years. Mean patients with RA treated per month was 125.6. The majority of rheumatologists reported having an infusion suite in their office $(80.6 \%)$.

\section{Openness to route of administration and attributes of biologic therapies}

Over half of patients were open to both IV and SQ administration (53.1\%) (Table 3). In contrast, rheumatologists reported that only a mean $40.7 \%$ of their patients would be open to both IV and SQ. Whereas rheumatologists thought $34.0 \%$ of patients would be open to SQ only, only $16.5 \%$ of patients reported openness to SQ only.

Table 2 Rheumatologist characteristics

\begin{tabular}{lll}
\hline & $\% /$ Mean \pm SD & $\mathbf{N}$ \\
\hline Age & $49.18 \pm 8.83$ & 103 \\
Female & 27.2 & 28 \\
White & 72.8 & 75 \\
Number of years in practice as rheumatologist & $14.42 \pm 6.39$ & 103 \\
Number of patients with RA treated per month & $125.58 \pm 51.38$ & 103 \\
Infusion suite in office & 80.6 & 83 \\
\hline
\end{tabular}

Abbreviations: RA, rheumatoid arthritis; SD, standard deviation.
Openness to attributes of biologic therapy administration frequency was highest for SQ administration every 4 weeks or monthly for both patients (mean=3.37) and rheumatologists (mean=4.29) (Table 3). Mean openness to an IV administration time of 30 minutes every 8 weeks was the third highest among both patients (mean=2.86) and rheumatologists (mean=3.75), below SQ administered every 2 weeks or 4 weeks and above preference for SQ once a week.

\section{Preferences for route of administration and attributes of biologic therapy}

A similar pattern emerged in the preference point allocations. The most preferred therapy option was SQ administered every 4 weeks or monthly by both patients (mean=35.1) and rheumatologists (mean=23.3) (Table 4). The second most preferred therapy option by patients was IV treatment administered for 30 minutes every 8 weeks (mean=13.9). However, rheumatologists reported that SQ treatment administered every 2 weeks would be the second most preferred therapy option by their patients (mean=14.6), followed by IV treatment administered for 30 minutes every 8 weeks (mean=13.1).

Whereas rheumatologists reported that $35.2 \%$ of their patients would strongly prefer SQ, only $26.3 \%$ of patients actually reported a strong preference for SQ (Table 4). In contrast, whereas rheumatologists reported that $31.3 \%$ of their patients would have no preference between SQ and IV administration, only $22.2 \%$ of patients reported no preference between the two routes of administration.

\section{Discrepancies between rheumatologist perceptions and patient preferences}

Several discrepancies emerged between rheumatologist perceptions and patient reports when stratified by key patient characteristics (Table 5). Rheumatologists believed that nearly half (48.6\%) of their older patients (aged 65 and older) would prefer IV, compared with none $(0.0 \%)$ of their younger 
Table 3 Patients' and rheumatologists' perceptions of patient openness to route of administration and attributes of biologic therapies

\begin{tabular}{|c|c|c|c|}
\hline & \multicolumn{2}{|c|}{$\begin{array}{l}\text { Patients } \\
(\mathbf{N}=\mathbf{2 4 3}) \\
\end{array}$} & \multirow{2}{*}{$\begin{array}{l}\text { Rheumatologists } \\
(\mathbf{N}=103) \\
\text { Mean } \% \pm \text { SD } \%\end{array}$} \\
\hline & $\%$ & $\mathbf{N}$ & \\
\hline \multicolumn{4}{|l|}{ Route of administration } \\
\hline IV only & 14.0 & 34 & $13.0 \pm 8.83$ \\
\hline SQ only & 16.5 & 40 & $34.0 \pm 19.6$ \\
\hline Both IV and SQ & 53.1 & 129 & $40.7 \pm 23.9$ \\
\hline \multirow[t]{2}{*}{ Neither } & 16.5 & 40 & $12.3 \pm 9.8$ \\
\hline & \multicolumn{2}{|c|}{ Mean \pm SD } & Mean \pm SD \\
\hline \multicolumn{4}{|l|}{ Attributes of biologic therapies } \\
\hline Self-injection, every 4 weeks or monthly & \multicolumn{2}{|c|}{$3.37 \pm 1.38$} & $4.29 \pm 0.60$ \\
\hline Self-injection, every 2 weeks & \multicolumn{2}{|c|}{$3.06 \pm 1.33$} & $3.95 \pm 0.65$ \\
\hline IV, taking 30 minutes, every 8 weeks & \multicolumn{2}{|c|}{$2.86 \pm 1.35$} & $3.75 \pm 0.79$ \\
\hline Self-injection, once a week & \multicolumn{2}{|c|}{$2.80 \pm 1.33$} & $3.43 \pm 0.72$ \\
\hline IV, taking 30 minutes, every 4 weeks & \multicolumn{2}{|c|}{$2.60 \pm 1.33$} & $3.30 \pm 0.85$ \\
\hline Self-injection, twice a week & \multicolumn{2}{|c|}{$2.44 \pm 1.22$} & $2.58 \pm 0.82$ \\
\hline IV, taking I hour, every 4 weeks & \multicolumn{2}{|c|}{$2.42 \pm 1.21$} & $3.15 \pm 0.80$ \\
\hline IV, taking 2 hours, every 8 weeks & \multicolumn{2}{|c|}{$2.33 \pm 1.22$} & $3.42 \pm 0.75$ \\
\hline IV, taking 2 hours, every 4 weeks & \multicolumn{2}{|c|}{$2.19 \pm 1.16$} & $2.79 \pm 0.79$ \\
\hline $\begin{array}{l}\text { IV, two infusions taking } 5 \text { hours, } \\
\text { separated by } 2 \text { weeks, every 16-24 weeks }\end{array}$ & \multicolumn{2}{|c|}{$2.13 \pm 1.24$} & $3.00 \pm 0.93$ \\
\hline
\end{tabular}

Notes: Presented for route of administration is the proportion of all patients reporting openness to each route and, as reported by rheumatologists, the mean proportion of patients estimated to be open to each route. Presented for attributes of biologic therapies are the mean openness ( $I=$ not at all open to $5=$ extremely open) of patients to each attribute, as reported by individual patients or as estimated by rheumatologists for the average patient.

Abbreviations: IV, intravenous infusion; SD, standard deviation; SQ, subcutaneous injection.

Table 4 Patient and rheumatologist perceptions of patient preferences for route of administration and attributes of biologic therapies

\begin{tabular}{|c|c|c|c|}
\hline & \multicolumn{2}{|c|}{$\begin{array}{l}\text { Patient } \\
(\mathrm{N}=\mathbf{2 4 3})\end{array}$} & \multirow{2}{*}{$\begin{array}{l}\text { Prescriber } \\
(\mathrm{N}=103) \\
\text { Mean } \% \pm \text { SD } \%\end{array}$} \\
\hline & $\%$ & $\mathbf{N}$ & \\
\hline \multicolumn{4}{|l|}{ Route of administration } \\
\hline Strongly prefer SQ & 26.3 & 64 & $35.2 \pm 24.4$ \\
\hline Somewhat prefer SQ & 23.0 & 56 & $17.0 \pm 11.5$ \\
\hline No preference & 22.2 & 54 & $31.3 \pm 26.4$ \\
\hline Somewhat prefer IV & 16.5 & 40 & $8.3 \pm 7.4$ \\
\hline \multirow[t]{2}{*}{ Strongly prefer IV } & 11.9 & 29 & $8.1 \pm 7.0$ \\
\hline & \multicolumn{2}{|c|}{ Mean \pm SD } & Mean \pm SD \\
\hline \multicolumn{4}{|l|}{ Attributes of biologic therapies } \\
\hline Self-injection, every 4 weeks or monthly & \multicolumn{2}{|c|}{$35.09 \pm 33.06$} & $23.28 \pm 13.56$ \\
\hline Self-injection, every 2 weeks & \multicolumn{2}{|c|}{$9.37 \pm 9.62$} & $14.63 \pm 7.40$ \\
\hline IV, taking 30 minutes, every 8 weeks & \multicolumn{2}{|c|}{$13.89 \pm 19.49$} & $13.10 \pm 8.59$ \\
\hline Self-injection, once a week & \multicolumn{2}{|c|}{$9.83 \pm 16.82$} & $11.34 \pm 11.24$ \\
\hline IV, taking 30 minutes, every 4 weeks & \multicolumn{2}{|c|}{$8.05 \pm 13.19$} & $8.02 \pm 6.34$ \\
\hline Self-injection, twice a week & \multicolumn{2}{|c|}{$5.45 \pm 11.01$} & $3.89 \pm 4.60$ \\
\hline IV, taking I hour, every 4 weeks & \multicolumn{2}{|c|}{$5.16 \pm 9.43$} & $6.23 \pm 4.70$ \\
\hline IV, taking 2 hours, every 8 weeks & \multicolumn{2}{|c|}{$5.08 \pm 9.73$} & $7.56 \pm 5.42$ \\
\hline IV, taking 2 hours, every 4 weeks & \multicolumn{2}{|c|}{$3.33 \pm 5.81$} & $4.54 \pm 3.44$ \\
\hline $\begin{array}{l}\text { IV, two infusions taking } 5 \text { hours, } \\
\text { separated by } 2 \text { weeks, every 16-24 weeks }\end{array}$ & \multicolumn{2}{|c|}{$4.77 \pm 10.48$} & $7.40 \pm 6.49$ \\
\hline
\end{tabular}

Notes: Presented for route of administration is the proportion of all patients reporting preference for each route and, as reported by rheumatologists, the mean proportion of patients estimated to prefer each route. Presented for attributes of biologic therapies are the mean preference point allocations ( 100 points distributed across attributes) of patients to each attribute, as reported by individual patients or as estimated by rheumatologists for the average patient.

Abbreviations: IV, intravenous infusion; SD, standard deviation; SQ, subcutaneous injection. 
Table 5 Rheumatologist perceptions of patient preferences versus patient preferences, stratified by patient characteristics

\begin{tabular}{|c|c|c|c|c|c|c|}
\hline & \multicolumn{3}{|l|}{ Patient } & \multicolumn{3}{|c|}{ Rheumatologist } \\
\hline & $\begin{array}{l}\text { Prefer SQ \% } \\
\text { (N) }\end{array}$ & $\begin{array}{l}\text { No preference \% } \\
\text { (N) }\end{array}$ & $\begin{array}{l}\text { Prefer IV \% } \\
\text { (N) }\end{array}$ & $\begin{array}{l}\text { Prefer SQ \% } \\
\text { (N) }\end{array}$ & $\begin{array}{l}\text { No preference \% } \\
\text { (N) }\end{array}$ & $\begin{array}{l}\text { Prefer IV \% } \\
\text { (N) }\end{array}$ \\
\hline Older $(\geq 65)$ & $51.2(22)$ & $27.9(12)$ & $20.9(9)$ & $9.7(10)$ & $41.7(43)$ & $48.5(50)$ \\
\hline Younger $(<65)$ & $49.0(98)$ & $21.0(42)$ & $30.0(60)$ & $68.9(7 I)$ & 3I.I (32) & $0.0(0)$ \\
\hline Male & $50.2(104)$ & $19.8(4 \mid)$ & $30.0(62)$ & $28.2(29)$ & $66.0(68)$ & $5.8(6)$ \\
\hline Female & $44.4(16)$ & $36.1(13)$ & $19.4(7)$ & $20.4(21)$ & $73.8(76)$ & $5.8(6)$ \\
\hline Medicare & $58.6(17)$ & $20.7(6)$ & $20.7(6)$ & $3.9(4)$ & $25.2(26)$ & $70.9(73)$ \\
\hline Medicaid & $50.8(30)$ & $18.6(11)$ & $30.5(18)$ & $18.4(19)$ & $63.1(65)$ & $18.4(19)$ \\
\hline Commercial insurance & $45.2(52)$ & $25.2(29)$ & $29.6(45)$ & $40.8(42)$ & $56.3(58)$ & $2.9(3)$ \\
\hline Employed & $50.5(48)$ & $25.3(24)$ & $24.2(23)$ & $72.8(75)$ & $25.2(26)$ & $1.9(2)$ \\
\hline Unemployed & $48.6(72)$ & $20.3(30)$ & $31.1(46)$ & $10.7(11)$ & $71.8(74)$ & $17.5(18)$ \\
\hline Advanced joint damage & $51.9(80)$ & $20.8(32)$ & $27.3(42)$ & $3.9(4)$ & $61.2(63)$ & $35.0(36)$ \\
\hline
\end{tabular}

Notes: Presented are row percentages within patients (ie, proportion of each patient subgroup endorsing a particular preference) and rheumatologists (ie, proportion of all rheumatologists believing that each patient subgroup endorses a particular preference).

Abbreviations: IV, intravenous infusion; SQ, subcutaneous injection.

patients. However, among older patients, only $21.0 \%$ reported a preference for IV, compared with $30.0 \%$ of younger patients. Whereas rheumatologists believed that only $9.7 \%$ of their older patients would prefer SQ, $51.1 \%$ of older patients actually reported a preference for SQ. Rheumatologists reported that $70.9 \%$ of patients insured with Medicare would prefer IV, whereas only $20.6 \%$ of Medicare patients actually reported a preference for IV. In contrast, rheumatologists reported low preference for SQ among Medicare patients (3.9\%), whereas $58.6 \%$ of Medicare patients reported preferring SQ. Rheumatologists reported low preference for IV among those who were employed (1.9\%), whereas $24.2 \%$ of employed patients reported preferring IV.

\section{Treatment initiation and treatment decision making}

With respect to treatment initiation, over half of patients surveyed (54.3\%) reported that the discussion regarding biologic therapy was initiated by their rheumatologist (Figure 1). Nearly a quarter of patients (23.5\%) reported being the ones to initiate discussion. Nearly half of patients surveyed reported that they would make the final decision regarding biologic therapies after considering their rheumatologist's recommendation (49.0\%) (Figure 2). However, only $21.8 \%$ reported sharing the decision-making process equally with their rheumatologist, and $24.7 \%$ reported making the decision themselves.

\section{Aspects of biologic therapies discussed by patients and rheumatologists}

Several discrepancies emerged with respect to aspects of biologic therapies discussed by patients and rheumatologists. The majority of rheumatologists reported discussing in detail the ability of biologics to slow (78.6\%) or stop (76.7\%) joint damage (Table 6). In contrast, a minority of patients reported discussing in detail biologics' ability to slow (28.8\%) or stop (23.5\%) joint damage. Whereas $77.7 \%$ of rheumatologists reported discussing in detail the ability of biologics to improve well-being and daily function, only $30.9 \%$ of patients reported the same level. Whereas $68.0 \%$ of rheumatologists reported discussing in detail the effectiveness of biologics compared with other treatments, only $26.3 \%$ of patients reported the same. About a third of patients reported discussing at least somewhat their IV (30.9\%) and SQ (34.2\%) experience. In contrast, the vast majority of rheumatologists reported discussing the IV (95.1\%) or

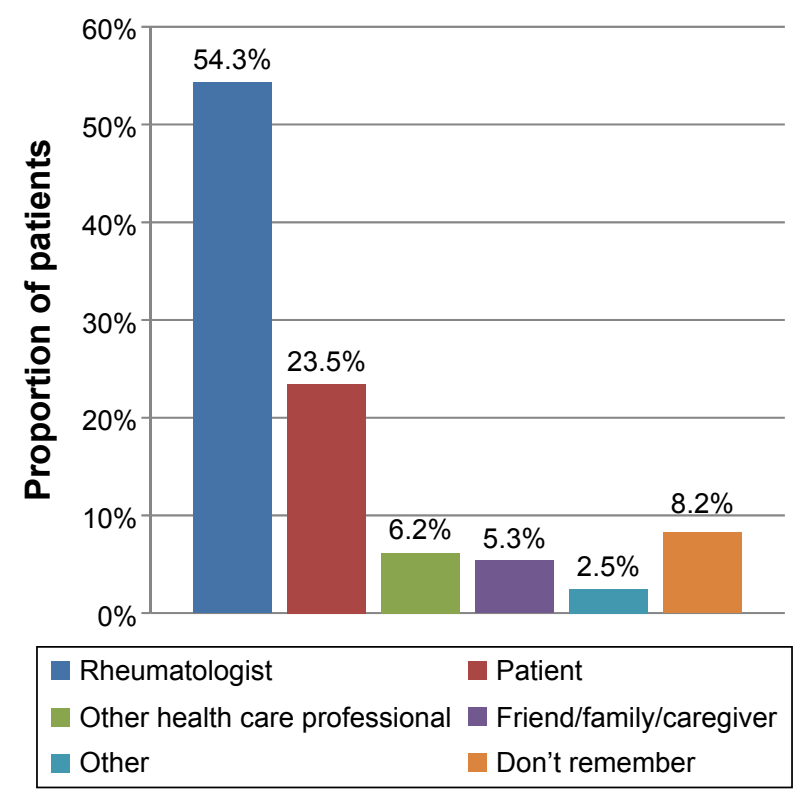

Figure I Person initiating discussion about starting biologic therapy. 


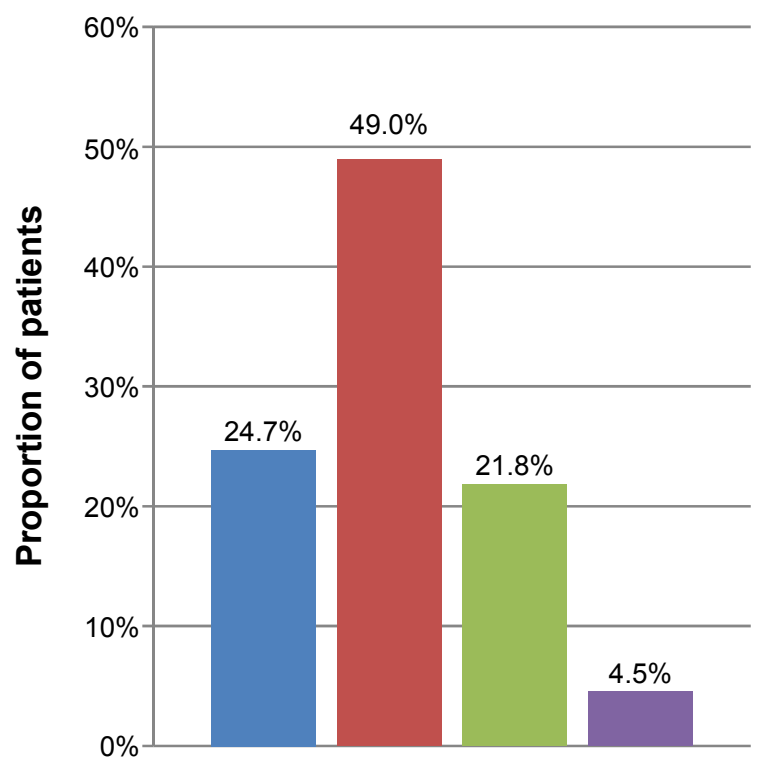

- I make the final treatment decision

- I make the final treatment decision after considering my rheumatologist's recommendation

- I share responsibility with my rheumatologist when deciding upon a treatment

- My rheumatologist makes the final treatment decision, but seriously considers my opinion

Figure 2 Patient's role in making final treatment decisions.

SQ $(99.0 \%)$ experience with their patients. Frequency of biologic therapy administration was reported being discussed by the majority of patients (74.1\%) and rheumatologists $(100.0 \%)$.

\section{Factors considered when making treatment decisions}

The majority of patients considered the impact of treatments on both their present and future condition when making treatment decisions (74.5\%), with only a small percentage considering the impact on present (14.8\%) or future $(9.9 \%)$ condition alone (Figure 3).

\section{Discussion}

The current study found that more patients may be open to both SQ and IV routes of biologic therapy administration than rheumatologists assume. Similarly, more patients may prefer the IV route of administration than rheumatologists perceive. The discrepancies between rheumatologists' perceptions of patients' preferences and actual patients' preferences regarding biologic therapies are consistent with prior studies indicating similar discrepancies. ${ }^{30}$ For instance, Willeke et al ${ }^{30}$ found that $94 \%$ of rheumatologists reported believing their patients would prefer SQ injections whereas the majority of patients $(63 \%)$ reported that they would prefer an infusion every 6-9 months.

Findings from the present study also demonstrated substantial variations in preferences among routes of administration across various types of patients based on demographic characteristics (eg, age) and insurance status, as well as in terms of rheumatologists' expectations. Consistent with the present findings, prior research has also shown that individual preferences among routes of administration were driven by patient characteristics, including: expectations of safety and convenience, past experience, and patients' perceptions of their disease state. ${ }^{31}$ The current findings build on this literature with a better understanding of the interplay between patient characteristics and preferences.

The present study examined separately patients' openness to and preferences among routes of administration (SQ and IV) and various attributes of biologic therapy, as these refer to distinct dimensions worthy of evaluation. On the one hand, our preference measures allow us to determine what patients would choose in a comparative, binary sense. Whereas, our openness measures allow us to determine in a noncomparative way what patients would evaluate as acceptable versus unacceptable, allowing the possibility of openness to multiple treatment options versus none. In tandem, these sets of results provide for a more comprehensive, transparent understanding of patients' attitudes than either dimension alone. For example, our results indicate that over half of patients were open to both IV and SQ, while at the same time, patients tended to prefer SQ over IV.

Whereas most studies of nondisease specific populations have found that a majority of patients prefer to leave decision making to their physicians, the current study found that nearly a quarter of patients reported initiating the discussion with their rheumatologist. ${ }^{28,29}$ However, over half of patients reported that their rheumatologist initiated the discussion to start biologic therapy. Most patients reported making treatment decisions after considering their rheumatologist's recommendation (approximately half) or sharing responsibility (about a fifth). This finding is in line with prior research, which demonstrates that the majority of patients with RA (95\%) report using a paternalistic decision-making model immediately after their diagnosis, but then many (74\%) of these patients evolve to utilizing shared decision making. ${ }^{32}$ These findings suggest that rheumatologists play a significant role in treatment decision making for patients with RA. 


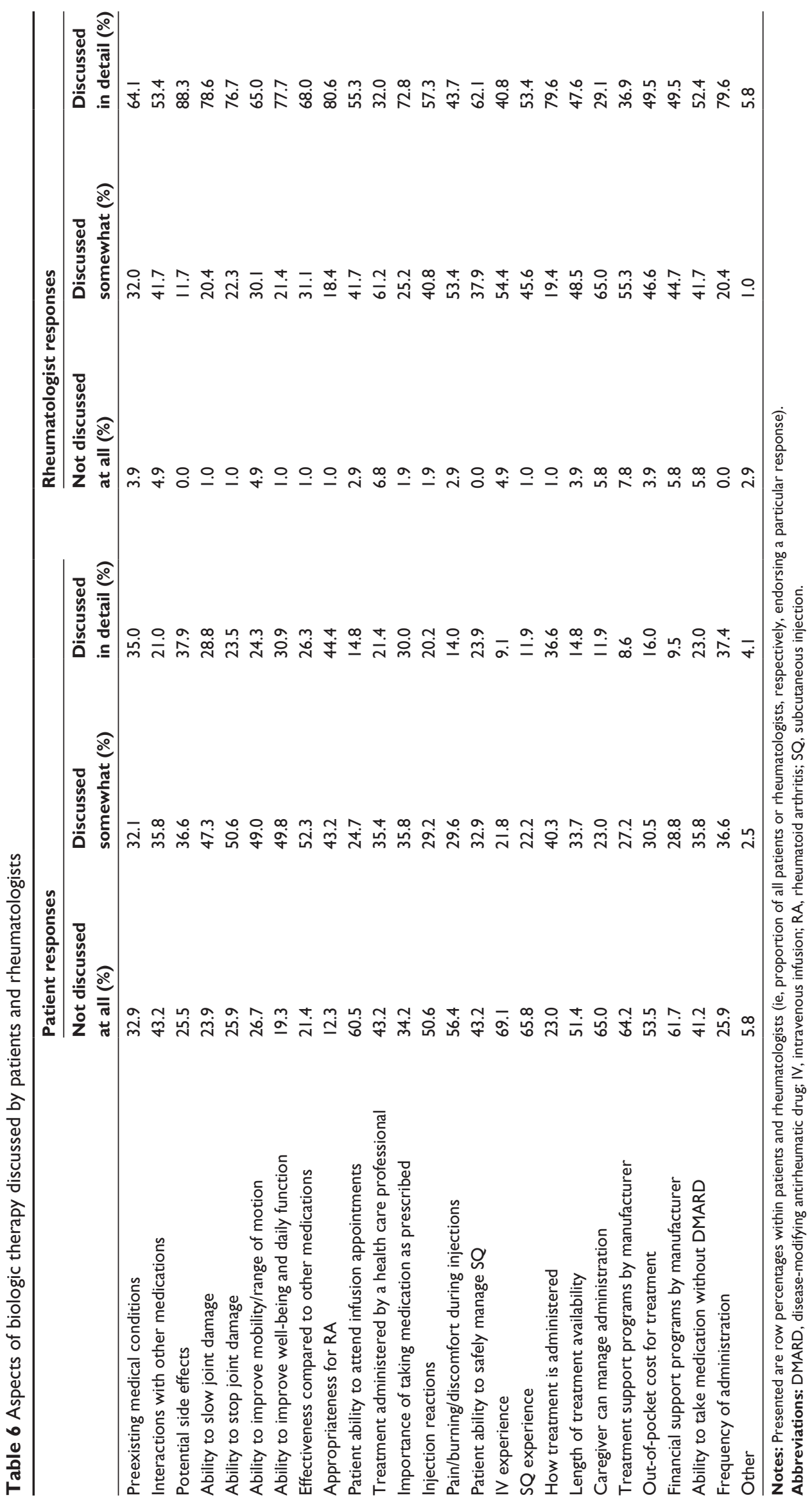


Mostly think about its impact on present condition

Mostly think about its impact on future

Both

Neither

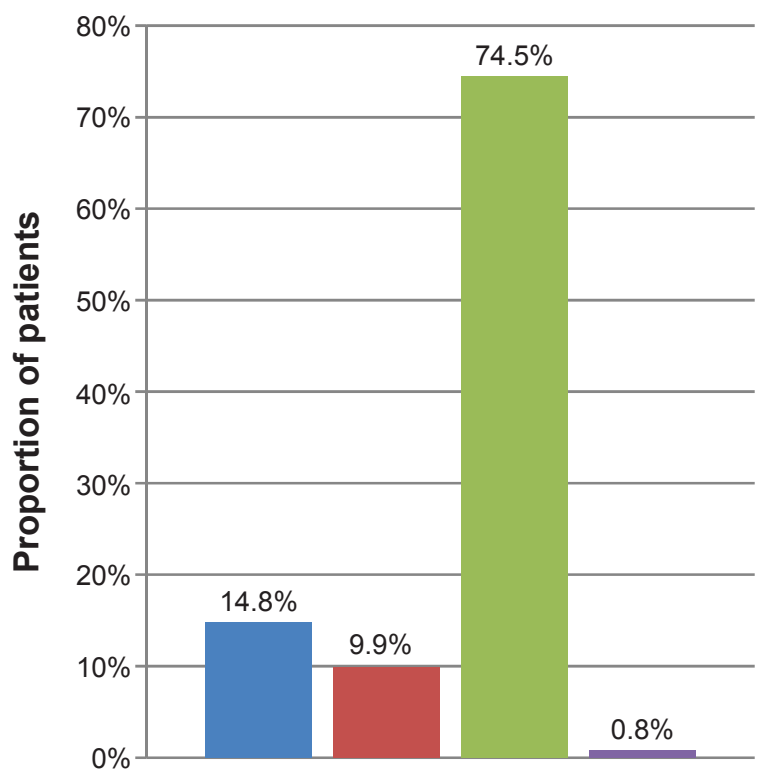

Figure 3 Temporal impact of RA considered by patients when making treatment decisions.

Abbreviation: RA, rheumatoid arthritis.

Despite rheumatologists' role in treatment decision making, a study by van Hulst et a ${ }^{16}$ indicated that patients and rheumatologists prioritize very different factors when making decisions regarding treatments. As such, it is critical to understand better the dialogue that occurs between patients and rheumatologists. When examining this dialogue, the present study found several discrepancies between patients' and rheumatologists' perceptions of the level of discussion provided around aspects of biologic therapy. Specifically, a larger proportion of rheumatologists than patients reported detailed discussion of potential side effects as well as the ability of biologics to slow or stop joint damage and improve well-being and daily functioning with their patients. Additionally, the majority of patients reported no discussion at all with their rheumatologist regarding SQ or IV infusion experience or the patient's ability to attend infusion appointments, whereas the majority of rheumatologists reported discussing these topics at least somewhat with their patients. Moreover, a higher proportion of rheumatologists than patients reported that all aspects of biologic therapies were discussed. This inconsistency may highlight a gap in communication in which rheumatologists either do discuss or perceive discussing aspects of biologic therapies more than patients either perceive hearing or do hear these aspects discussed. Future research should examine actual clinical encounters to pinpoint the source of the discrepancy and whether misperceptions reside primarily among rheumatologists, patients, or both, as well as whether issues, such as lack of comprehension on the part of patients and lack of clarity on the part of physicians may contribute to any biases. Improved understanding of communications within clinical encounters can help inform which aspects of communication should be targeted for the most effective intervention.

These discussions between patients and their rheumatologists are critical, as they influence patients' and rheumatologists' decisions regarding biologic therapies. Inconsistencies in patient and rheumatologist preferences and beliefs indicate a break in communication that needs to be addressed in order to improve patient care. Not only have patients indicated a high need for information about RA and treatment options $^{28,29}$ but also prior research indicates that a high level of information received was strongly correlated with patients' involvement in the treatment decision-making process. ${ }^{33}$ The discrepancies in communication outlined in the present study could exert a substantial influence on the decision to initiate biologic therapy. Thus, providing patients with the appropriate information regarding these critical aspects of biologic therapies could empower more patients to make the decision to escalate care to biologic therapy in a timely fashion. In fact, a systematic review of the literature $(n=15$ studies) found that most patients required more information related to their treatment and disease. ${ }^{34}$ Communicating this information might alleviate some patient concerns, such as the discontinuation of therapy, which has been known to affect patients' decision making regarding RA treatment. ${ }^{35}$

The differences in reports of what was discussed as well as patients' actual preferences for which aspects of biologic therapy to discuss with their rheumatologist might influence patients' final decision regarding which biologic therapy to utilize. Because of discrepancies in reports of which aspects of biologic therapy were discussed in these clinical contexts, shared decision making is all the more important in this context. Prior research on shared decision making indicates that critical steps include both patients and physicians sharing information, building consensus about preferred treatments, and coming to a shared agreement on which treatment to implement. ${ }^{36}$ Furthermore, shared decision-making models acknowledge that patients and physicians may have different values and preferences - hence the need to build toward reaching consensus on the appropriate treatment. ${ }^{37}$ Shared decision-making approaches could thus overcome differences between information that patients would like regarding 
biologic therapies and information the rheumatologists share, ensuring that patients are able to engage in treatment decisions aligned with their own values and preferences. The current study was not designed to assess the association between discussion topic preferences and patients' final decisions regarding biologic treatment; therefore, future research should examine this link to further inform opportunities for alignment in patient-provider communication.

In regard to treatment decision making, the majority (nearly three-quarters) of patients in the present study reported considering primarily the impact of treatment on their current condition as a factor taken into consideration. This finding is consistent with a previous study showing that $63.8 \%$ of respondents would not change their therapy as long as their condition did not worsen. ${ }^{26}$ Furthermore, results of the present study are consistent with prior research indicating that patients are more motivated to maintain their current condition than to think about future prognosis. ${ }^{26}$ Namely, only $9.9 \%$ of patients in the present study reported thinking about their future health alone when making treatment decisions.

Despite the novel addition of this study to our understanding of the openness to, preferences for, and discrepancies in communication regarding biologic therapy for RA, there are limitations that should be considered. One of the main limitations of this study is the use of an online data collection method. This approach did not yield a random sample; however, this was minimized by the recruitment of the sample from two sources, an advocacy group and a consumer panel. This sampling approach yielded substantial variation across the groups and prevented a bias toward a single patient type. Another limitation of the study is that the surveys were cross-sectional, depicting patients' and rheumatologists' perspectives at a single point in time. As such, these perspectives could potentially change based on symptom changes or functional declines. Additionally, this sample was highly educated, which could potentially affect patients' preferences among treatment options. A majority of the patients in both samples were white and, therefore, noted racial disparities between white and black patients in terms of treatment aggressiveness (eg, lower among black patients with similar disease severity ${ }^{38}$ ) may not have been captured in these data. Rheumatologists' prior experiences with specific biologic agents may have influenced their perceptions and preferences among these therapies; this in turn could have introduced bias into our results, to the extent that 1) our physician sample was not representative of the overall population of physicians and 2) physician and practice characteristics that differed from those of the population were correlated with different preferences among therapeutic options. This potential bias would not be expected among patients, given that they had no prior experience using biologic agents. Finally, patient and rheumatologist data were not linked in this study, thus limiting insight into a precise estimation of the source of disconnect between patients and their corresponding rheumatologist in discussions regarding their treatment options. A patient-rheumatologist link would also have enabled an understanding of the potential influence of the relationship itself on the decision-making process.

\section{Conclusion}

Studies have found that patients with RA trust and would benefit from the guidance of their rheumatologists in the decision-making process. ${ }^{20}$ Thus, there is a strong need for thorough discussions of all available treatment options and patient preferences between patients and their rheumatologists. Additionally, profiles of patients based on demographic variables should not influence rheumatologists' perceptions of patients' preferences or priorities, as expectations may frequently be misaligned. Given discrepancies in patient-rheumatologist perceptions around discussions, and considering the substantial role of rheumatologists in the decision-making process ${ }^{32}$ (both initiating treatment and guiding patients), it is important to address dialogue between patients and rheumatologists to ensure transparency and improve understanding of patients' needs and preferences.

\section{Acknowledgments}

The authors acknowledge Hema Kannan Gandhi, MPH, for her contribution to literature review and developing the detailed outline of the manuscript with funding from Janssen Scientific Affairs, LLC. The authors acknowledge Megan Shen, $\mathrm{PhD}$, assistant professor at Weill Cornell Medicine, for her contribution to literature review and writing on behalf of Kantar Health with funding from Janssen Scientific Affairs, LLC.

Janssen Scientific Affairs, LLC provided funding for this manuscript and the study upon which it is based. Kantar Health conducted the study with funding from Janssen Scientific Affairs, LLC.

\section{Author contributions}

All authors contributed to the study design, interpretation of results, and review, revision, and approval of the final manuscript. Authors have access to the study data supporting this publication. Duncan Brown, Amir Goren, and Susan C Bolge contributed to data analysis. 


\section{Disclosure}

Susan C Bolge is an employee of Janssen Scientific Affairs, LLC, which funded this study and a stockholder of parent company Johnson \& Johnson. Seth Ginsberg is an employee of Global Healthy Living Foundation (GHLF), which is the parent nonprofit of Creaky Joints. GHLF received funding from Janssen Scientific Affairs, LLC for data collection and consulting on this study. Isabel Allen is an employee of UCSF. Amir Goren and Duncan Brown were employees of Kantar Health at the time the study was conducted. Kantar Health received funding from Janssen Scientific Affairs, LLC for conducting, analyzing, and reporting on this study. The authors report no other conflicts of interest in this work.

\section{References}

1. Kvien TK. Epidemiology and burden of illness of rheumatoid arthritis. Pharmacoeconomics. 2004;22(1):1-12.

2. Ong KL, Wu BJ, Cheung BM, Barter PJ, Rye K-A. Arthritis: its prevalence, risk factors, and association with cardiovascular diseases in the United States, 1999 to 2008. Ann Epidemiol. 2013;23(2):80-86.

3. Barton JL. Patient preferences and satisfaction in the treatment of rheumatoid arthritis with biologic therapy. Patient Prefer Adherence. 2009; 3:335-344.

4. Firestein GS. Evolving concepts of rheumatoid arthritis. Nature. 2003;423(6937):356-361.

5. Dougados M, Soubrier M, Antunez A, et al. Prevalence of comorbidities in rheumatoid arthritis and evaluation of their monitoring: Results of an international, cross-sectional study (COMORA). Ann Rheum Dis. 2014;73(1):62-68.

6. Newhall-Perry K, Law N, Ramos B, et al. Direct and indirect costs associated with the onset of seropositive rheumatoid arthritis. J Rheumatol. 2000;27(5):1156-1163.

7. Furneri G, Mantovani L, Belisari A, et al. Systematic literature review on economic implications and pharmacoeconomic issues of rheumatoid arthritis. Clin Exp Rheumatol. 2012;30(4):S72.

8. Singh JA, Furst DE, Bharat A, et al. 2012 Update of the 2008 American College of Rheumatology recommendations for the use of disease-modifying antirheumatic drugs and biologic agents in the treatment of rheumatoid arthritis. Arthritis Care Res. 2012;64(5): 625-639.

9. Singh JA, Christensen R, Wells GA, et al. Biologics for rheumatoid arthritis: an overview of Cochrane reviews. Cochrane Database Syst Rev. 2009;4(4):CD007848.

10. Doan QV, Chiou C-F, Dubois RW. Review of eight pharmacoeconomic studies of the value of biologic DMARDs (adalimumab, etanercept, and infliximab) in the management of rheumatoid arthritis. J Manag Care Pharm. 2006;12(7):555-569.

11. Iannone F, Lopalco G, Cantarini L, Galeazzi M, Lapadula G. Efficacy and safety of combination therapy for preventing bone damage in rheumatoid arthritis. Clin Rheumatol. 2016;35(1):19-23.

12. Smolen JS, Landewé R, Breedveld FC, et al. EULAR recommendations for the management of rheumatoid arthritis with synthetic and biological disease-modifying antirheumatic drugs: 2013 update. Ann Rheum Dis. 2013;65(8):2005-2014.

13. Keystone EC, Kavanaugh AF, Sharp JT, et al. Radiographic, clinical, and functional outcomes of treatment with adalimumab (a human anti-tumor necrosis factor monoclonal antibody) in patients with active rheumatoid arthritis receiving concomitant methotrexate therapy: A randomized, placebo-controlled, 52-week trial. Arthritis Rheum. 2004; 50(5):1400-1411.
14. Saag KG, Teng GG, Patkar NM, et al. American College of Rheumatology 2008 recommendations for the use of nonbiologic and biologic disease-modifying antirheumatic drugs in rheumatoid arthritis. Arthritis Rheum. 2008;59(6):762-784.

15. Scott D. Biologics-based therapy for the treatment of rheumatoid arthritis. Clin Pharmacol Ther. 2012;91(1):30-43.

16. Van Hulst L, Kievit W, Van Bommel R, van Riel P, Fraenkel L. Rheumatoid arthritis patients and rheumatologists approach the decision to escalate care differently: results of a maximum difference scaling experiment. Arthritis Care Res. 2011;63(10):1407-1414.

17. Huynh TK, Østergaard A, Egsmose C, Madsen OR. Preferences of patients and health professionals for route and frequency of administration of biologic agents in the treatment of rheumatoid arthritis. Patient Prefer Adherence. 2014;8:93-99.

18. Curkendall S, Patel V, Gleeson M, Campbell R, Zagari M, Dubois R. Compliance with biologic therapies for rheumatoid arthritis: Do patient out-of-pocket payments matter? Arthritis Rheum. 2008;59(10): $1519-1526$.

19. Bolge SC, Goren A, Tandon N. Reasons for discontinuation of subcutaneous biologic therapy in the treatment of rheumatoid arthritis: A patient perspective. Patient Prefer Adherence. 2015;9:121-131.

20. Lisicki R, Chu L. What matters to patients and physicians when considering biologic therapy for rheumatoid arthritis. Postgrad Med. 2008;120(3):154-160.

21. Williams E, Edwards C. Patient preferences in choosing anti-TNF therapies-R1. Rheumatology (Oxford). 2006;45(12):1575-1576.

22. Augustovski F, Beratarrechea A, Irazola V, et al. Patient preferences for biologic agents in rheumatoid arthritis: A discrete-choice experiment. Value Health. 2013;16(2):385-393.

23. Poulos C, Hauber AB, González JM, Ogale S, Turpcu A. Patient tradeoffs between frequency and duration of biologic treatments for rheumatoid arthritis. Poster presented at: The ISPOR 17th Annual International Meeting. Washington, DC, on June 2-6, 2012. [abstract] Value in Health. 2012; 15(4):A42.

24. Thompson A. Practical aspects of therapeutic intervention in rheumatoid arthritis. J Rheumatol Suppl. 2009;82:39-41.

25. Kievit W, Van Hulst L, Van Riel P, Fraenkel L. Factors that influence rheumatologists' decisions to escalate care in rheumatoid arthritis: Results from a choice-based conjoint analysis. Arthritis Care Res. 2010; 62(6):842-847.

26. Wolfe F, Michaud K. Resistance of rheumatoid arthritis patients to changing therapy: Discordance between disease activity and patients' treatment choices. Arthritis Rheum. 2007;56(7):2135-2142.

27. Benhamou M, Rincheval N, Roy C, et al. The gap between practice and guidelines in the choice of first-line disease modifying antirheumatic drug in early rheumatoid arthritis: results from the ESPOIR cohort. J Rheumatol. 2009;36(5):934-942.

28. Levinson W, Kao A, Kuby A, Thisted RA. Not all patients want to participate in decision making: A national study of public preferences. J Gen Intern Med. 2005;20(6):531-535.

29. Stevenson FA, Barry CA, Britten N, Barber N, Bradley CP. Doctorpatient communication about drugs: The evidence for shared decision making. Soc Sci Med. 2000;50(6):829-840.

30. Willeke P, Becker H, Wassenberg S, Pavenstädt H, Jacobi A. [Patient/ rheumatologist evaluation of infusion treatment for rheumatoid arthritis]. Z Rheumatol. 2011;70(3):232-234.

31. Scarpato S, Antivalle M, Favalli EG, et al. Patient preferences in the choice of anti-TNF therapies in rheumatoid arthritis. Results from a questionnaire survey (RIVIERA study). Rheumatology (Oxford). 2010; 49(2):289-294.

32. Mathews AL, Coleska A, Burns PB, Chung KC. The evolution of patient decision-making regarding medical treatment of rheumatoid arthritis. Arthritis Care Res (Hoboken). 2016;68(3):318-324.

33. Neame R, Hammond A, Deighton C. Need for information and for involvement in decision making among patients with rheumatoid arthritis: a questionnaire survey. Arthritis Rheum. 2005;53(2):249-255. 
34. Dilla T, Rentero ML, Comellas M, Lizan L, Sacristán JA. Patients' preferences for rheumatoid arthritis treatments and their participation in the treatment decision-making process. A systematic review of the literature. Value Health. 2015;18(7):A652.

35. Sanderson T, Calnan M, Morris M, Richards P, Hewlett S. The impact of patient-perceived restricted access to anti-TNF therapy for rheumatoid arthritis: a qualitative study. Musculoskeletal Care. 2009;7(3): 194-209.

36. Charles C, Gafni A, Whelan T. Shared decision-making in the medical encounter: what does it mean? (or it takes at least two to tango). Soc Sci Med. 1997;44(5):681-692.
37. Montgomery A, Fahey T. How do patients' treatment preferences compare with those of clinicians? Qual Health Care. 2001;10(suppl 1): i39-i43.

38. Constantinescu F, Goucher S, Weinstein A, Fraenkel L. Racial disparities in treatment preferences for rheumatoid arthritis. Med Care. 2009; 47(3):350-355.

\section{Publish your work in this journal}

Patient Preference and Adherence is an international, peer-reviewed, open access journal that focuses on the growing importance of patient preference and adherence throughout the therapeutic continuum. Patient satisfaction, acceptability, quality of life, compliance, persistence and their role in developing new therapeutic modalities and compounds to optimize clinical outcomes for existing disease states are major areas of interest for the journal. This journal has been accepted for indexing on PubMed Central. The manuscript management system is completely online and includes a very quick and fair peer-review system, which is all easy to use. Visit http://www. dovepress.com/testimonials.php to read real quotes from published authors.

Submit your manuscript here: http://www.dovepress.com/patient-preference-and-adherence-journal 